\title{
ANALISIS PENGENDALIAN PERSEDIAAN SISTEM MANAJEMEN PERSEDIAAN BAHAN BAKU KEMASAN
}

\author{
Suryani, Dedi Can \\ Program Studi Manajemen, Sekolah Tinggi Ilmu Ekonomi Al-Khairiyah \\ Email: soerjanie10@gmail.com; dedican_can@yahoo.com
}

\begin{abstract}
Abstrak-Persediaan merupakan salah satu hal yang harus diperhatikan oleh perusahaan. Salah satu caranya adalah dengan pengelolaan manajemen persediaan. Permasalahan yang terjadi pada lokasi penelitian adalah adanya kekurangan dan kelebihan stok untuk bahan baku kemasan. Kekurangan stok ini dikarenakan tidak adanya perhitungan untuk jumlah safety stock dan reorder point, penyebab terjadinya kelebihan stok adalah kelebihan tidak adanya pengelompokan bahan baku kemasan untuk mengetahui produk mana yang lebih penting sesuai dengan permintaan. Analisa perbaikan sistem difokuskan pada bahan baku kemasan. Berdasarkan hasil pengolahan data diperoleh dari 304 bahan baku kemasan yang ada, terdapat 15 bahan baku kemasan yang berada di kelas $A$. Pengolahan difokuskan pada kelas $A$ saja. Perhitungan forecasting dengan menggunakan software SPSS. Dan pengolahan dilanjutkan dengan menggunakan metode lot size-reorder point systems dengan hasil quantity, reorder point dan safety stock yang berbeda-beda 15 bahan baku sesuai dengan perhitungan yang dilakukan.
\end{abstract}

Kata kunci : Persediaan; Quantity; Reorder Point; Safety Stock

\begin{abstract}
Inventory is one of the things that must be considered by the company. One way is to manage inventory management. The problem that occurs in the research location is the lack and excess stock for packaging raw materials. This lack of capital is due to the absence of calculations for the number of safety stock and reorder points, the cause of excess inventory is the excess in the absence of groupings of packaging raw materials to find out which products are more critical according to demand. Analysis of system improvements focuses on packaging raw materials. Based on the results of data processing obtained from 304 existing packaging raw materials, there are 15 packaging raw materials in class $A$. Processing is focused on class $A$ only. Forecast calculations using SPSS software. And processing is continued by using the size-reorder point systems lot method with quantity results, reorder margin and safety stock that varies 15 raw materials according to the calculations performed.
\end{abstract}

Keywords : Inventory; Quantity; Reorder Point; Safety Stock

\section{PENDAHULUAN}

Salah satu faktor yang mempengaruhi kelancaran proses produksi adalah bahan baku yang selalu tersedia pada saat dibutuhkan. Persediaan yang mencukupi akan mampu menjaga kestabilan proses produksi. Perencanaan persediaan mempunyai tantangan untuk menyediakan kebutuhan produksi dengan meminimalkan stock yang ada untuk mengefisienkan biaya stock yang menjadi beban perusahaan.

Perencanaan persediaan merupakan salah satu teknik dalam menetapkan kebutuhan bahan baku berdasarkan jumlah volume, jumlah periode pemesanan dengan memperhatikan fasilitas yang tersedia (Arif , Supriyadi, \& Cahyadi, 2017). Perencanaan persediaan bahan baku mempunyai manfaat meminimalkan resiko keterlambatan bahan baku, dan mampu menyediakan kebutuhan bahan baku bagi produksi sehingga bahan baku tidak menumpuk berlebihan (Assauri, 1999).

Salah satu metode yang digunakan untuk menganalisa persediaan bahan baku adalah Lot Size-Reorder Point Model. Pemesanan dilakukan pada saat pemesanan sudah berada pada titik pemesanan kembali dengan ukuran pemesanan yang tetap (Bahagia, 2006; Maisarah, Prassetiyo, \& Rispianda, 2015). Metode ini digunakan pada saat permintaan tiap bulan tidak stabil. 
Masalah yang biasa timbul pada PT. ICP adalah terjadinya kekurangan dan kelebihan stok bahan baku kemasan. Kekurangan stok ini dikarenakan tidak adanya perhitungan untuk jumlah safety stock dan reorder point. Akibatnya adalah mengakibatkan mundurnya jadwal produksi dan harus memesan bahan baku tersebut dalam waktu yang singkat. Sedangkan penyebab terjadinya kelebihan stok adalah kelebihan tidak adanya pengelompokan bahan baku kemasan untuk mengetahui produk mana yang lebih penting sesuai dengan permintaan. Akibatnya adalah maka gudang menjadi penuh hanya karena bahan baku kemasan saja. Selain itu akibat lain yang bisa terjadi adalah kualitas untuk bahan baku kemasan menjadi turun. Hal ini dikarenakan bahan baku kemasan berada di gudang lebih lama dari usia pakai dari bahan baku kemasan tersebut. Sehingga saat digunakan, perlu adanya perbaikan bahan baku kemasan atau bahkan pergantian dengan bahan baku kemasan yang baru. Rumusan masalah pada penelitian ini adalah bagaimana manajemen persediaan bahan baku kemasan yang dapat digunakan untuk mengatasi permasalahan kekurangan dan kelebihan stok pada PT ICP.

Tujuan penelitian menentukan kebutuhan bahan baku yang berkategori A berdasarkan metode lot size-reorder point systems. Hasil penelitian ini diharapkan menjadi referensi perusahaan dalam menentukan persediaan bahan baku untuk meminimalkan biaya tambahan yang diperlukan terutama untuk biaya simpan

\section{METODE PENELITIAN}

Penelitian ini dimulai dengan mengidentifikasi kebutuhan bahan baku dengan metode $A B C$, pemilihan hasil peramalan dengan metode holt, brown dan simple seasional serta menentukan kebutuhan bahan baku hasil peramalan menggunakan lot size-reorder point systems. Data yang digunakan adalah data historis perusahaan mengenai kebutuhan baku yang sudah ada.

Analisis ABC (Always Better Control), merupakan sebuah analisis untuk mengklasifikan persediaan yang ada kedalam tiga kategori berdasarkan nilai penggunaannya berdasarkan hukum pareto yang bertujuan untuk merencanakan persediaan bahan baku yang mempunyai jumlah yang banyak (Ballou, 2007). Untuk item yang memiliki nilai tinggi untuk penggunaan dan dalam jumlah sedikit masuk ke dalam kelas $A$ dan berada dalam kontrol yang ketat. Kelas $\mathrm{C}$ adalah untuk item dalam jumlah besar tetapi memiliki nilai penggunaan yang sedikit dan berada di bawah kontrol yang sederhana. Sedangkan untuk kelas B adalah untuk item yang berada di nilai moderat dan akan berada dibawah kontrol tingkat menengah.

Peramalan (forecasting) merupakan proses perkiraan kebutuhan bahan baku di masa mendatang yang berkaitan dengan aspek kualitas, waktu maupun tempat yang membutuhkan bahan baku (Haming \& Mahfud, 2014). Pemilihan metode peramalan berdasarkan data historis dari data aktual kebutuhan perusahaan dan hasil peramalan yang mempunyai MAD (mean absolute deviation absolut) yang paling kecil yang dapat digunakan untuk proses peramalan (Supriyadi, \& Riskiyadi, 2016).

Metode pemulusan eksponensial linear dari Brown adalah hampir sama dengan rata-rata bergerak linier dengan menggunakan data yang bersifat linier. Metode pemulusan eksponensial linear dari Holt, pada prinsipnya sama dengan Brown dan hanya berbeda dari cara memuluskan nilai trend dengan parameter yang berbeda dibandingkan parameter pada deret asli (Noeryanti, \& Andriyani, 2012). Metode Simple seasonal adalah model pemulusan eksponensial yang mirip dengan metode ARIMA dengan nol perintah autoregresi, satu urutan differencing, satu urutan differencing musiman, dan perintah 1 , $p$, dan $p+1$ dari rata-rata bergerak, di mana $p$ adalah jumlah periode dalam interval musiman.

Hasil peramalan ini selanjutnya akan digunakan untuk menghitung dengan menggunakan metode perhitungan lot sizereorder point systems.. Dalam perhitungan menggunakan lot size-reorder point systems, diperlukan beberapa data tambahan yaitu ratarata, standar deviasi, biaya penalti, tabel $Z$ dan tabel $\mathrm{L}(\mathrm{z})$

\section{HASIL DAN PEMBAHASAN}

Analisis ABC (Always Better Control), merupakan sebuah analisis untuk mengklasifikan persediaan yang ada kedalam tiga kategori berdasarkan nilai penggunaannya berdasarkan lead time dan biaya bahan baku (Tabel 1). Untuk item yang memiliki nilai tinggi untuk penggunaan dan dalam jumlah sedikit masuk ke dalam kelas A dan berada dalam kontrol yang ketat. Kelas C adalah untuk item dalam jumlah besar tetapi memiliki nilai penggunaan yang sedikit dan berada di bawah kontrol yang sederhana. Sedangkan untuk kelas B adalah untuk item yang berada di nilai moderat dan akan berada dibawah kontrol tingkat menengah.

Hasil analisis ABC mengikuti prosedur persediaan normal di beberapa organisasi yang mengikuti pola sebagai berikut (Samak-Kulkarni 
\& Rajhans, 2013):

1. 5 sampai $10 \%$ dari total jumlah item untuk 70 sampai $80 \%$ dari nilai penggunaan tahunan.

2. 10 sampai $20 \%$ dari total jumlah item untuk 15 sampai $20 \%$ dari nilai penggunaan tahunan.

3. 70 sampai $80 \%$ dari total jumlah item selama 5 sampai $15 \%$ dari nilai penggunaan tahunan.

Berdasarkan hasil pengumpulan data, maka didapat sebanyak 304 bahan baku kemasan. Kemudian dari data tersebut dilakukan pengolahan dengan menggunakan metode $A B C$ Analisis untuk menentukan bahan baku kemasan yang penting. Setelah itu didapat sebanyak 15 bahan baku kemasan yang termasuk dalam kelas A, dimana jumlah tersebut merupakan $80 \%$ dari total penggunaan bahan baku kemasan, untuk kelas B sebanyak 71, dimana jumlah tersebut merupakan $15 \%$ dari total penggunaan bahan baku kemasan dan untuk kelas C sebanyak 217, dimana jumlah tersebut merupakan $5 \%$ dari total penggunaan bahan baku kemasan. Dari hasil tersebut, terlihat bahwa bahan baku kemasan yang berada di kelas $A$ merupakan bahan baku kemasan yang penting. Dimana bahan baku tersebut merupakan bahan baku kemasan untuk produk-produk utama sehingga fokus penelitian ini hanya bahan baku yang berada di kelas $A$..

Tabel 1. Lead Time dan Biaya

\begin{tabular}{ccccc}
\hline Kode & $\begin{array}{c}\text { Lead Time } \\
\text { (hari) }\end{array}$ & Holding Cost & Order Cost & Penalty Cost (Rp) \\
\hline $0037-\mathrm{G}$ & 15 & $(\mathrm{Rp})$ & $(\mathrm{Rp})$ & \\
$0053-\mathrm{K}$ & 10 & 3,678 & 10,000 & 1,567 \\
$0227-\mathrm{F}$ & 20 & 967 & 10,000 & 2,873 \\
$0040-\mathrm{H}$ & 9 & 432 & 10,000 & 572 \\
$0043-\mathrm{K}$ & 18 & 135 & 10,000 & 267 \\
$0228-\mathrm{F}$ & 5 & 254 & 10,000 & 100 \\
$0019-\mathrm{H}$ & 20 & 1,965 & 10,000 & 127 \\
$0023-\mathrm{J}$ & 13 & 2,379 & 10,000 & 1,024 \\
$0380-\mathrm{F}$ & 8 & 692 & 10,000 & 1,627 \\
$0085-\mathrm{G}$ & 10 & 489 & 10,000 & 398 \\
$0306-\mathrm{E}$ & 20 & 1,624 & 10,000 & 215 \\
$0001-\mathrm{J}$ & 25 & 2,742 & 10,000 & 520 \\
$0043-\mathrm{H}$ & 5 & 311 & 10,000 & 1,468 \\
$0401-\mathrm{E}$ & 12 & 689 & 10,000 & 103 \\
$0025-\mathrm{O}$ & 7 & 31,628 & 10,000 & 372 \\
$0004-\mathrm{J}$ & 27 & 1,950 & 10,000 & 15,890 \\
\hline
\end{tabular}

Selanjutnya perhitungan akan difokuskan kepada bahan baku kemasan yang berada di kelas A. Dari data permintaan yang ada, maka selanjutnya dilakukan perhitungan menggunakan forecasting yang bertujuan untuk mengetahui peramalan permintaan di masa mendatang. Dengan menggunakan data history dua tahun kebelakang, maka didapat hasil perhitungan forecasting untuk permintaan satu tahun kedepan. Perhitungan forecasting dilakukan menggunakan software SPSS. Dari 16 data yang ada, didapat bahwa dengan menggunakan model forecasting terbaik adalah dengan menggunakan model simple seasonal yang mempunyai nilai RMSE, MAPE dan MAE yang paling kecil.

Setelah diketahui metode yang terbaik, maka selanjutnya metode tersebut digunakan untuk melakukan peramalan setahun ke depan. Hasil peramalan ini selanjutkan akan digunakan untuk menghitung dengan menggunakan metode perhitungan lot size-reorder point systems. Dalam perhitungan menggunakan lot sizereorder point systems, diperlukan beberapa data tambahan yaitu rata-rata, standar deviasi, biaya penalti, tabel $Z$ dan tabel L(z). Sebelumnya juga diperlukan beberapa tahap perhitungan untuk menghitung besar $Q$ dan Rnya. Setelah dihitung Q0, langkah selanjutnya adalah menghitung besar $R$ dengan menggunakan tabel $Z$. Kemudian dilakukan beberapa iterasi sampai didapat besar quantity $(\mathrm{Q})$ dan reorder point $(\mathrm{R})$ sama atau mendekati nilai sebelumnya. Dimana keadaan tersebut merupakan keadaan dikatakan sudah optimal. 
Jurnal INTECH Teknik Industri Universitas Serang Raya Vol 4 No 2 Desember 2018, 65-70 p-ISSN 2407-781X, e-ISSN 2655-2655

Tabel 2. Perbandingan Hasil RMSE, MAPE dan MAE

\begin{tabular}{|c|c|c|c|c|}
\hline Kode & Akurasi Error & RMSE & MAPE (\%) & MAE \\
\hline & Holt & $71,632.60$ & 63.87 & $54,734.84$ \\
\hline \multirow[t]{3}{*}{ 0037-G } & Brown & $720,820.86$ & 66.90 & $56,885.75$ \\
\hline & Simple Seasonal & $51,347.41$ & 39.79 & $37,827.98$ \\
\hline & Holt & $157,820.99$ & 45.53 & $127,306.39$ \\
\hline \multirow[t]{3}{*}{ 0053-K } & Brown & $161,467.68$ & 49.49 & $129,160.18$ \\
\hline & Simple Seasonal & $102,008.78$ & 23.11 & $68,002.88$ \\
\hline & Holt & $44,495.95$ & 67.06 & $33,815.15$ \\
\hline \multirow[t]{3}{*}{ 0227-F } & Brown & $47,798.45$ & 74.95 & $38,418.96$ \\
\hline & Simple Seasonal & $26,872.13$ & 32.07 & $22,015.79$ \\
\hline & Holt & $30,452.224$ & 74.109 & $23,149.021$ \\
\hline \multirow[t]{3}{*}{$0040-\mathrm{H}$} & Brown & $30,900.934$ & 79.777 & $23,963.941$ \\
\hline & Simple Seasonal & $24,161.048$ & 53.432 & $17,748.203$ \\
\hline & Holt & $16,510.343$ & 58.205 & $13,232.706$ \\
\hline \multirow[t]{3}{*}{ 0043-K } & Brown & $16,725.928$ & 58.490 & $13,424.818$ \\
\hline & Simple Seasonal & $11,466.062$ & 24.435 & $7,813.806$ \\
\hline & Holt & $13,594.022$ & 44.715 & $10,403.696$ \\
\hline \multirow[t]{3}{*}{ 0228-F } & Brown & $13,925.227$ & 52.412 & $11,122.242$ \\
\hline & Simple Seasonal & $8,730.589$ & 24.530 & $5,896.523$ \\
\hline & Holt & $65,606.894$ & 52.409 & $47,514.306$ \\
\hline \multirow[t]{3}{*}{ 0019-H } & Brown & $65,341.103$ & 52.377 & $48,283.176$ \\
\hline & Simple Seasonal & $49,487.760$ & 35.344 & $37,149.991$ \\
\hline & Holt & $80,178.566$ & 35.236 & $62,404.533$ \\
\hline \multirow[t]{3}{*}{ 0023-J } & Brown & $81,987.358$ & 34.691 & $62,799.793$ \\
\hline & Simple Seasonal & $56,541.901$ & 21.881 & $45,687.214$ \\
\hline & Holt & $43,551.552$ & 135.689 & $28,176.092$ \\
\hline \multirow[t]{3}{*}{ 0380-F } & Brown & $42,714.104$ & 130.836 & $30,620.128$ \\
\hline & Simple Seasonal & $49,487.760$ & 35.344 & $37,149.991$ \\
\hline & Holt & $15,836.626$ & 55.138 & $11,116.523$ \\
\hline \multirow[t]{3}{*}{ 0085-G } & Brown & $16,208.320$ & 70.277 & $12,449.640$ \\
\hline & Simple Seasonal & $7,487.868$ & 24.638 & $5,109.251$ \\
\hline & Holt & $45,641.352$ & 69.093 & $35,488.804$ \\
\hline \multirow[t]{3}{*}{ 0306-E } & Brown & $47,751.669$ & 77.254 & $37,376.120$ \\
\hline & Simple Seasonal & $28,395.162$ & 33.834 & $22,681.431$ \\
\hline & Holt & $71,077.470$ & 38.572 & $52,843.666$ \\
\hline \multirow[t]{3}{*}{ 0001-J } & Brown & $70,381.179$ & 37.433 & $52,717.215$ \\
\hline & Simple Seasonal & $51,244.521$ & 24.723 & $38,605.684$ \\
\hline & Holt & $16,269.442$ & 65.500 & $12,144.394$ \\
\hline \multirow[t]{3}{*}{ 0043-H } & Brown & $16,082.468$ & 68.656 & $12,393.537$ \\
\hline & Simple Seasonal & $7,605.325$ & 26.029 & $5,509.171$ \\
\hline & Holt & $24,288.645$ & 46.929 & $17,061.835$ \\
\hline \multirow[t]{3}{*}{ 0401-E } & Brown & $25,832.244$ & 56.811 & $18,506.027$ \\
\hline & Simple Seasonal & $21,689.063$ & 38.221 & $15,625.290$ \\
\hline & Holt & $1,141.737$ & 63.158 & 823.480 \\
\hline \multirow[t]{2}{*}{ 0025-O } & Brown & $1,142.264$ & 72.365 & 832.767 \\
\hline & Simple Seasonal & 872.735 & 48.706 & 672.396 \\
\hline
\end{tabular}


Setelah didapat perhitungan dan besar quantity $(Q)$ dan reorder point (R) maka diperlukan perhitungan safety stock yang bertujuan agar PT ICP dapat mengetahui berapa jumlah aman yang harus tersedia. Safety stock ini diperlukan untuk mengatasi terjadinya kekurangan stok.berupa kesimpulan khusus dan kesimpulan umum. Kesimpulan khusus merupakan hasil analisa data atau hasil uji hipotesa tentang fenomena yang diteliti. Kesimpulan umum sebagai hasil generalisasi atau keterkaitan dengan fenomena serupa di wilayah lain dari publikasi terdahulu. Hal yang perlu diperhatikan adalah segitiga konsistensi (masalah-tujuan-kesimpulan harus konsisten).

Contoh perhitungan untuk 0228-F:

Mean: 14,237.07

Standard Deviation: 7,850.29

Unit Price: $718,749.72$

Holding Cost: 254

Order Cost: 10,000

Penalty Cost: 127

Lead Time: 5

Langkah 1: menghitung expected annual demand

$$
\begin{aligned}
& \text { Expected annual demand = mean } \times 12 \\
& \quad=14,37.07 \times 12 \\
& \quad=170,844.8
\end{aligned}
$$

Langkah 2: menghitung demand during lead time

$=\frac{\text { expected annual demand }}{\text { number of day in year }} x$ lead time

$=\frac{170,844.8}{365} \times 5=2,340.34$

Langkah 3: menghitung annual variance

Annual variance $=(\text { standard deviation })^{2} \times 12$

$=(7,850.29)^{2} \times 12=739,524,147.73$

Langkah 4: menghitung variance of lead time demand

$$
\begin{aligned}
& \text { Variance of } \quad \begin{array}{l}
\text { lead } \\
\text { demand= annual variance }
\end{array} \frac{\text { lead time }}{\text { days } \text { in year }} \\
& =739,524,157.73 \times \frac{5}{365}=3,182.34
\end{aligned}
$$

time

Langkah 5: menghitung EOQ

$E O Q=Q 0=\frac{2 k \lambda}{h}=\frac{\begin{array}{l}2 \times 10,000 x \\ 170,844.8\end{array}}{254}=3,667.7$

Langkah 6: menghitung $F(R 1)$

$$
F R 1=1-\frac{Q 0 . h}{p \lambda}=1-\frac{3667.74 \times 254}{127 \times 170,844.8}=0.9571
$$

Dengan menggunakan tabel $\mathrm{z}$, maka dengan hasil $F(R 1)=0.9571$ didapatkan besar $z=1.72$. Dan dengan menggunakan tabel $\mathrm{L}(\mathrm{z})$, dengan nilai $z=1.72$ maka $L(z)=0.0174$

Langkah 7: menghitung $\mathrm{R}(1)$

$R 1=\sigma z+\mu=3,183.13 \times 1.72+2,340.49=$ $7,814.82$

Langkah 8: menghitung $N(R 1)$

$N(R 1)=\sigma L(z)=3183.13 \times 0.0174=55.381$

Langkah 9: menghitung Q1

$$
\mathrm{Q} 1=\frac{2 \lambda[k+p N}{\mathrm{R} 1]}=\frac{2 \times 170,856+[127 \times}{\mathrm{h}}=\frac{55.381]}{254}
$$

Q1 $=4,786.85$

Dengan membandingkan hasil dengan Q0, maka dilakukan iterasi sampai didapat nilai yang mendekati.

Langkah 10: menghitung $F(R 2)$

$F R 2=1-\frac{Q 1 . h}{p \lambda}=1-\frac{4,786,844.8 \times 254}{127 \times 170,844.8}=0.9440 \quad$ Z $=1,59$

Langkah 11: menghitung $\mathrm{R}(2)$

$\mathrm{R} 2=\sigma z+\mu=3,183.13 \times 1.59+2,340.49=$ $7,401.05$

Dengan membandingkan hasil dengan nilai $\mathrm{R} 1$, didapat nilai R2 dan R1 mendekati. Iterasi berhenti sampai disini.

Langkah 12: menghitung safety stock

$$
S S=R-\mu=7401.05-2340.34=5,060.71
$$

Berdasarkan langkah tersebut maka akan diperoleh nilai Quantity, Reorder Point dan Safety Stock (Tabel 3) untuk bahan baku kemasan yang berada di kelas A.Setiap produk memiliki jumlah iterasi yang berbeda-beda. Iterasi berhenti jika sudah didapat hasil yang optimal 
Jurnal INTECH Teknik Industri Universitas Serang Raya Vol 4 No 2 Desember 2018, 65-70 p-ISSN 2407-781X, e-ISSN 2655-2655

Tabel 2.Hasil Perhitungan Quantity, Reorder Point dan Safety Stock

\begin{tabular}{|c|c|c|c|}
\hline Kode & Quantity & Reorder Point & Safety Stock \\
\hline 0037-G & $22,947.40$ & $154,711.63$ & 78663.58752 \\
\hline 0053-K & $36,360.92$ & $158,298.58$ & 101263.6335 \\
\hline 0227-F & $22,877.70$ & $110,201.66$ & 51475.46778 \\
\hline $0040-\mathrm{H}$ & $9,271.78$ & $28,644.04$ & 17664.31697 \\
\hline 0043-K & $8,055.29$ & $19,252.97$ & 8763.173743 \\
\hline 0228-F & $4,786.85$ & $7,401.05$ & 5060.714928 \\
\hline 0019-H & $8,055.29$ & $19,252.97$ & 65396.99359 \\
\hline 0023-J & $4,786.85$ & $7,401.05$ & 79738.60534 \\
\hline $0380-\mathrm{F}$ & $24,942.40$ & $169,173.07$ & 44929.88701 \\
\hline $0085-G$ & $7,861.50$ & $22,740.15$ & 13240.84666 \\
\hline 0306-E & $22,201.56$ & $97,958.71$ & 38127.25134 \\
\hline 0001-J & $31,787.67$ & $31,787.67$ & 79583.72346 \\
\hline $0043-\mathrm{H}$ & $7,503.44$ & $12,906.03$ & 8471.358846 \\
\hline 0401-E & $6,938.17$ & $33,378.07$ & 14372.26892 \\
\hline $0025-\mathrm{O}$ & 227.46 & $1,315.22$ & 742.5251808 \\
\hline 0004-J & $30,954.53$ & $209,721.00$ & 69402.43339 \\
\hline
\end{tabular}

\section{KESIMPULAN}

Berdasarkan perhitungan dengan metode analisis $A B C$ diperoleh 15 bahan baku kemasan yang termasuk dalam kelas $A$, dimana jumlah tersebut merupakan $80 \%$ dari total penggunaan bahan baku kemasan, untuk kelas B sebanyak 71 , dimana jumlah tersebut merupakan $15 \%$ dari total penggunaan bahan baku kemasan dan untuk kelas C sebanyak 217, dimana jumlah tersebut merupakan $5 \%$ dari total penggunaan bahan baku kemasan. Peramalan yang digunakan menggunakan metode seasonal yang mempunyai hasil RMSE, MAPE dan MAE terkecil. Implementasi metode lot size-reorder point systems menghasilkan quantity, reorder point dan safety stock yang berbeda-beda 15 bahan baku sesuai dengan perhitungan yang dilakukan.

\section{DAFTAR PUSTAKA}

Arif, M., Supriyadi, S., \& Cahyadi, D. (2017). Analisis Perencanaan Persediaan Batubara FX Dengan Metode Material Requirement Planning. Jurnal Manajemen Industri Dan Logistik, 1(2), 53-60.

Assauri, S. (1999). Manajemen Produksi dan Pengendalian Produksi. Edisi Revisi, Jakarta: Lembaga Penerbit Fakultas Ekonomi Universitas Indonesia.

Bahagia

$$
\text { S. N. (2006). }
$$

Sistem
Inventori. Bandung: Penerbit ITB.

Ballou, R. H. (2007). Business logistics/supply chain management: planning, organizing, and controlling the supply chain. India: Pearson Education.

Haming, M. \& Mahfud N. (2014) Manajemen Produksi Modern: Operasi Manufaktur dan Jasa Buku 1. Jakarta: PT. Bumi Aksara. 2014.

Maisarah, D., Prassetiyo, H., \& Rispianda, R. (2015). Rancangan Sistem Persediaan Bahan Baku Kertas Menggunakan Metode Single Item Single Supplier Dan Multi Item Single Supplier di CV. Dwimuharam Putra. REKA INTEGRA, 3(3), 63-74

Noeryanti, E. O., \& Andriyani, F. (2012). Aplikasi Pemulusan Eksponensial Dari Brown Dan Dari Holt Untuk Data Yang Memuat Trend.Seminar Nasional Aplikasi Sains \& Teknologi (SNAST) Periode III (pp 447-455)

Samak-Kulkarni, D. S., \& Rajhans, D. N. (2013). Determination of Optimum Inventory Model for Minimizing Total Inventory Cost. Procedia Engineering , 803-809.

Supriyadi, S., \& Riskiyadi, R. (2016). Penjadwalan Produksi IKS-Filler Pada Proses Ground Calcium Carbonate Menggunakan Metode MPS di Perusahaan Kertas. Sinergi: Jurnal Teknik Mercu Buana, 20(2), 157-164. 